\title{
Kjøring med mistanke om påvirkning av andre rusmidler enn alkohol
}

\author{
Asbjørg S. Christophersen, Svetlana Skurtveit og Jørg Mørland \\ Statens rettstoksikologiske institutt, Postboks 9934 Ila, 0132 Oslo
}

\begin{abstract}
SAMMENDRAG
Statens rettstoksikologiske institutt har i løpet av de siste år registrert en stor økning av prøver fra bilførere mistenkt for kjøring under påvirkning av andre rusmidler enn alkohol. Antall positive saker økte $42 \%$ fra 1994 til 1995. De hyppigste påviste stoffer er tetrahydrocannabinol, amfetamin, benzodiazepiner og opiater (morfin/kodein). Bruk av tyngre narkotiske stoffer har blitt mer vanlig i trafikksammenheng og antall positive tilfeller har økt betydelig mer enn totalt antall saker. Fra 1994 til 1995 økte antall positive amfetaminprøver med 75\% (fra 533 til 937) og antall positive prøver som følge av heroininntak økte med 87\% (fra 92 til 172). Bruk av flere stoffer samtidig er vanlig, over $60 \%$ av sakene i 1995 var positive på mer enn ett stoff, alkohol ikke medregnet. De fleste tilfeller var representert av menn i alderen 25-32 år (37\%). Kvinner var representert i ca. $11 \%$ av sakene.
\end{abstract}

Christophersen AS, Skurtveit S, Mørland J. Drivers suspected to drive under the influence of drugs other than alcohol. Nor J Epidemiol 1996; 6 (1): 45-48.

\section{ENGLISH SUMMARY}

The National Institute of Forensic Toxicology has registered a large increase in the number of samples from drivers suspected to drive under influence of drugs other than alcohol. The number of drug positive cases increased $42 \%$ from 1994 to 1995 . The most frequent drugs detected are tetrahydrocannabinol, amphetamine, benzodiazepines and opiates (morphine/codeine). The frequency of hard narcotic drug use has increased more than the total number of cases. From 1994 to 1995, the number of amphetamine positive samples increased $75 \%$ (from 533 to 937 ) and the number of samples positive due to heroin use (detection of the metabolite 6monoacetylmorphine in urine) increased $87 \%$. Multi-drug use is common and more than one drug was detected in more than $60 \%$ of the cases from 1995, alcohol not included. Most of the cases were represented by men $25-32$ years old (37\%). Women were represented in about $11 \%$ of the cases.

\section{INNLEDNING}

I følge den norske veitrafikkloven er det forbudt å føre motorvogn under påvirkning av alkohol eller andre berusende eller bedøvende midler. Straffereaksjonen er knyttet til blodalkoholkonsentrasjonen (BAK) og graderes vanligvis $\mathrm{i}$ området $0,5-1,0$ promille (bot eller betinget fengsel), 1,0-1,5 promille (bot og betinget eller ubetinget fengsel), mens BAK over 1,5 promille fører til ubetinget fengsel. I alle tilfeller blir førerkortet inndratt for minst 2 år. Andre berusende eller bedøvende midler omfatter illegale stoffer, legemidler med rusmiddelpotensiale og løsemidler (sniffestoffer). Det finnes ingen grenser for påvirkning av slike stoffer, hverken i Norge eller noe annet land som vi kjenner til og hver sak må vurderes individuelt. Loven gir derimot rom for at straffeutmålingen kan gjenspeile graden av totalpåvirkning, slik at tilleggspåvirkning av andre rusmidler tas med i vurderingen når slike stoffer kombineres med alkohol og BAK er mindre enn 1,5 promille. Denne artikkelen beskriver sakene der politiet mistenker kjøring under påvirkning av andre rusmidler enn alkohol, utviklingen gjennom de siste år med økende antall tilfeller, samt endring i bruksmønster for forskjellige typer rusmidler.

\section{FRA BILFØRER STANSES AV POLITI - TIL SAKEN EVENTUELT HAVNER I RETTEN}

De fleste sjåfører mistenkt for påvirket kjøring blir stanset av politiet på grunn av ulykke, uforsvarlig 
eller uvanlig kjøring, eller andre grunner som gir politiet spesiell grunn til mistanke. Kun 10-15\% blir pågrepet i rutinekontroll. Politiet har den avgjørende rolle ved vurdering om mistanken skal rettes kun mot alkoholpåvirkning eller mot andre rusmidler. Ved mistanke om kun alkohol, tas en blodprøve som analyseres ved Statens rettstoksikologiske institutt (SRI) på kun alkohol. ${ }^{1}$

Dersom mistanken rettes mot andre rusmidler, skal blodprøvetaking kombineres med klinisk undersøkelse. Ved SRI analyseres blodprøvene både på alkohol og screenes på de mest vanlige av andre rusmidler (amfetamin, benzodiazepiner (BZD), cannabis, opiater, barbiturater og kokain), ved hjelp av en immunologisk metode (EMIT) og eventuelt gasskromatografiske (GC) metoder. Dersom BAK er mindre enn 1,5 promille, blir positive screeningresultater bekreftet og konsentrasjonen i blod bestemt med spesifikke kromatografiske metoder (GC/MS, GC, HPLC). Prøver med BAK over 1,5 promille blir vanligvis ikke analysert videre, da bilføreren blir dømt til ubetinget fengsel uansett.

Analyseresultatene returneres politiet sammen med primærfortolkning basert på resultatene og opplysning fra klinisk undersøkelse. For et stort antall saker ønsker politiet i tillegg en fullstendig sakkyndig uttalelse. Denne baseres på analyseresultater, klinisk undersøkelse, politirapport fra den aktuelle hendelse, avhør av siktede med opplysning om rusmiddelvaner og inntak av rusmiddel i forhold til når kjøring fant sted, samt vurdering av eventuelt toleranseutvikling. Det finnes ingen samlet oversikt over hvor mange slike saker som havner i retten. I følge oversikt fra Statisk sentralbyrå blir ca. 6000 personer pr. år dømt for påvirket kjøring. Denne statistikk skiller imidlertid ikke mellom tilfeller med kun alkoholpåvirkning og tilfeller med andre rusmidler. På grunnlag av en undersøkelse som nå foregår ved SRI, viser foreløpige resultater for 1992 at ca. $12-15 \%$ av dommene skyldes andre rusmidler. I 1995/1996 antas denne prosentandelen å være vesentlig høyere.

\section{UTVIKLINGEN GJENNOM DE SISTE 12 ÅR}

I løpet av de siste 12 år er antall tilfeller med mistanke om kun alkoholpåvirkning blitt halvert, fra ca. 10500 personprøver i 1983 til 5448 prøver i 1995. Antall tilfeller med mistanke om andre rusmidler har i samme tidsperiode blitt mer enn tredoblet, fra ca. 900 personprøver i 1983 til 3329 i 1995 (figur 1). Andre rusmidler enn alkohol representerer nå nærmere $40 \%$ av totalt antall tilfeller med mistanke om påvirket kjøring. Av 3329 saker i 1995, ble 3159 analysert videre på andre stoffer. For de resterende 170 saker var BAK > 1,5\%, slik at politiet ikke ønsket videre analyser på andre rusmidler.

${ }^{1}$ Fra 16. mars 1996 er det innført analyse av alkohol i utåndingsluft ved et fåtall politikamre $(<10)$
Fra 1994 til 1995 ble det registrert en signifikant økning i frekvensen av prøver med positive analysefunn i forhold til analyserte prøver $(\mathrm{n}=1495$ i 1994 $(59 \%), \mathrm{n}=2114$ i 1995 (67\%), $\mathrm{p}<0,001)$. I perioden 1992-1994 var det liten endring i antall prøver med positive analysefunn (tabell 1). Aldersgruppen 25-32 år representerte den største andel av prøvene (37\%), $29 \%$ var under 25 år, mens aldersgruppene 33-40 år og over 40 år var representert ved hhv. 17\% og 16\% av prøvene. Kvinner representerte ca. $11 \%$ av prøvene med andre rusmidler og ca. $8 \%$ av tilfellene med kun alkohol. Det er vanskelig å sammenligne utviklingen av våre analysefunn med politiets kontrollintensitet og generell bruk av illegale stoffer, da det ikke foreligger samlet statistikk som dekker de siste årene og som er oppdatert til og med 1995.

En tidligere undersøkelse av bilførere dømt for promillekjøring viste at over $40 \%$ ble tatt på nytt $\mathrm{i}$ løpet av de følgende fem år (1). Foreløpige resultater fra en pågående undersøkelse av bilførere som bruker andre rusmidler viser en høyere residivismefrekvens sammenlignet med de som ble tatt på grunnlag av kun alkoholpåvirkning.

\section{ENKELTSTOFFER - POSITIVE ANALYSEFUNN}

De stoffer som påvises oftest utenom alkohol er tetrahydrocannabinol (THC, aktivt virkestoff i cannabis), amfetamin og BZD (diazepam, flunitrazepam, oxazepam, nitrazepam, klonazepam). Stoffer som tilhører opiatgruppen (morfin, kodein) påvises også relativt hyppig. For flere av disse stoffene er det registrert en betydelig økning i positive analysefunn fra 1992 til 1995 , som er betydelig større enn økningen av det totale antall positive saker (tabell 1). Dette indikerer at politiet har større treffsikkerhet i sin mistanke om andre rusmidler, og at bruk av flere stoffer samtidig er et økende problem. Den mest dramatiske økning er registrert for amfetamin, med ca. 75\% (tabell 1). Forekomst av amfetamin i trafikksaker var relativt konstant fra slutten av 80-årene og frem til og med $1991(\mathrm{n}=216)$, mens det $\mathrm{i}$ forhold til dette året har vært en økning på over 300\% frem til 1995 ( $\mathrm{n}=937)$. Også for mindre frekvente stoffer har det skjedd en betydelig økning. Spesielt kan nevnes klonazepam, som foreskrives vesentlig $i$ behandling av epileptikere. Dette stoffet ble knapt påvist for 3-4 år siden, mens det $\mathrm{i}$ løpet av et år har vært en fordobling $i$ antall positive tilfeller $(\mathrm{n}=36$ i $1994, \mathrm{n}=91 \mathrm{i}$ 1995). Heroin $^{2}$ var tidligere ikke blant de mest frekvente stoffer i trafikksaker, men også her har det skjedd en betydelig økning, fra 27 positive tilfeller i 1992, 92 i 1994 til 172 tilfeller i 1995 (tabell 1).

\footnotetext{
${ }^{2}$ Heroin metaboliseres raskt i kroppen til 6-monoacetylmorfin (6MAM) og videre til morfin. Inntak av heroin dokumenteres ved påvisning av 6-MAM i urin eller blod.
} 


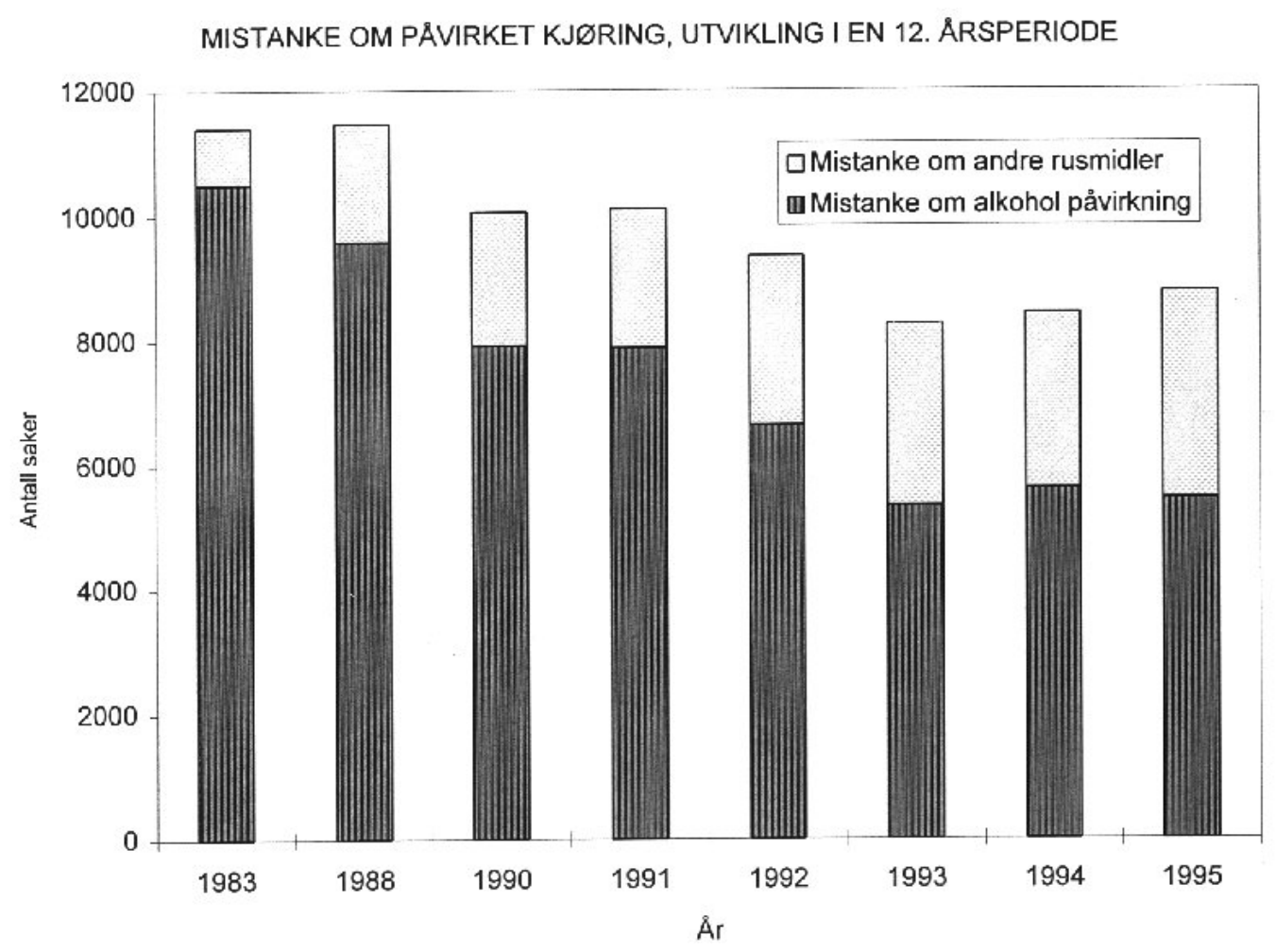

Figur 1. Antall tilfeller med mistanke om kjøring under påvirkning av alkohol og/eller andre rusmidler i Norge. Utvikling over en 12 -års periode.

Tabell 1. Totalt antall saker med positive analysefunn fra bilførere mistenkt for påvirket kjøring, samt totalt antall funn av enkeltstoffer (n) for årene 1992, 1993, 1994 og 1995. Frekvensen av enkeltfunn (\%) i forhold til totalt antall positive saker er oppgitt i parentes.

\begin{tabular}{|c|c|c|c|c|c|}
\hline Stoffnavn & $\begin{array}{c}1992 \\
\mathrm{n}=1415\end{array}$ & $\begin{array}{c}1993 \\
\mathrm{n}=1408\end{array}$ & $\begin{array}{c}1994 \\
\mathrm{n}=1495\end{array}$ & & $\begin{array}{l}995 \\
2114 \\
\end{array}$ \\
\hline THC & $842 \quad(59,5)$ & $741 \quad(52,6)$ & $660 \quad(44,1)$ & 995 & $(47,1)$ \\
\hline Amfetamin & $391 \quad(27,6)$ & $475 \quad(33,7)$ & $533 \quad(35,7)$ & 937 & $(44,3)$ \\
\hline Diazepam & $676 \quad(47,8)$ & $541 \quad(48,4)$ & $577 \quad(38,6)$ & 712 & $(33,7)$ \\
\hline Flunitrazepam & $212 \quad(15,0)$ & $221 \quad(15,7)$ & $198 \quad(13,2)$ & 270 & $(12,8)$ \\
\hline Morfin & $107 \quad(7,6)$ & $142 \quad(10,1)$ & $193 \quad(12,9)$ & 261 & $(12,4)$ \\
\hline Kodein & $(6,1)$ & $(9,3)$ & $104 \quad(7,0)$ & 113 & $(5,4)$ \\
\hline Klonazepam & $(1,2)$ & $(0,6)$ & $(2,4)$ & 91 & $(4,3)$ \\
\hline Oxazepam & $52 \quad(3,7)$ & $(4,6)$ & $(4,5)$ & 105 & $(5,0)$ \\
\hline 6-MAM (urin) & $29 \quad(2,1)$ & $(4,5)$ & $(6,2)$ & 172 & $(8,1)$ \\
\hline
\end{tabular}

\section{KOMBINASJONSBRUK}

Bruk av flere stoffer samtidig har vært vanlig. I de 2114 positive saker fra 1995 ble det gjort over 4000 enkeltfunn. To eller flere stoffer ble påvist $\mathrm{i}$ over 60 $\%$ av prøvene, alkohol ikke medregnet. Legemidler påvises ofte $\mathrm{i}$ kombinasjon med illegale stoffer eller alkohol og oftest i konsentrasjoner langt over det som er vanlig ved terapeutiske doser. En gjennomgang av analyseresultater fra 1992 og 1994 viste at over 90\% av prøvene som var positive på BZD, inneholdt enten illegale stoffer (ca. 60\%), alkohol (ca. 30\%) eller andre BZD (5-10\%). Forekomst av BZD var signifikant høyere hos kvinner $(39,7 \%)$ enn hos menn $(29,7 \%)(2)$.

\section{ENDRING I BRUKSMØNSTER}

Antall positive enkeltfunn har delvis øket parallelt med økning i totalt antall saker. Derimot viser fre- 
kvensen av stoffunn i positive saker at bruksmønsteret har endret seg (tabell 1). Den prosentvise endring er således uavhengig av politiets intensitet med hensyn på å rekvirere analyser på slike stoffer, da alle disse prøver har fulgt et standard analyseprogram.

Frekvensen av THC-funn i prøver med positivt analysefunn, falt fra nesten $60 \%$ i 1992 til $47 \%$ i 1995 , mens frekvensen av positive amfetaminprøver økte fra nærmere $28 \%$ til nærmere $44 \%$ i tilsvarende tidsperiode. Frekvensen av diazepam falt fra nærmere $48 \%$ i 1992 til under 34\% i 1995, forekomst av flunitrazepam og oxazepam har vært relativt konstant, mens forekomst av klonazepam har øket mange ganger. Frekvensen av 6-MAM (heroin) økte fra $2 \%$ i 1992 til over 8\% i 1995 (tabell 1). Dette viser at bruk av tyngre narkotiske stoffer (amfetamin, heroin) har blitt mer vanlig i trafikksammenheng, mens frekvensen av bruk av cannabis og enkelte BZD er noe redusert. Vi har tidligere vist at det er en korrelasjon mellom totalforbruket av BZD i et fylke og positive analysefunn i blodprøver fra bilførere mistenkt for påvirket kjøring (3).

\section{DISKUSJON}

Resultater fra rutinemateriale analysert ved SRI viser at kjøring under påvirkning av andre rusmidler enn alkohol er et betydelig problem. En undersøkelse fra 1987 og 1988 på et representativt utvalg av prøver fra bilførere mistenkt kun for alkoholpåvirkning, viste at
$38 \%$ inneholdt andre rusmidler enn alkohol (4). En ny undersøkelse fra 1993 viste at nærmere $15 \%$ av bilførere tatt på grunn av kun alkoholmistanke, hadde brukt andre rusmidler (5). I mellomtiden var antall alkoholsaker redusert, mens antall saker med andre rusmidler var øket betydelig (figur 1). Disse undersøkelsene viser at det norske politiet har fokusert på problemet og er flinke til å oppdage tilfeller med annen ruspåvirkning, da antall tilfeller med positive analysefunn har øket betydelig det siste året (41\%). Norge ligger samtidig på verdenstoppen i antall slike saker. En undersøkelse av rutinemateriale fra 1992 viste at Norge hadde 10-50 ganger flere tilfeller pr. innbygger, sammenlignet med land som Sverige, Danmark, Nederland og England (6). Samtidig har undersøkelser av trafikkdrepte bilførere i Norge (7) og bilførere involvert i ulykker (8), vist både lavere og høyere forekomst av andre rusmidler, sammenlignet med tilsvarende undersøkelser fra andre land. Dette indikerer at andre land sannsynligvis har et høyt mørketall i forekomst av andre rusmidler blant bilførere, som ikke oppdages på grunn av manglende rutine for håndtering av slike saker, lovgivning og mindre fokusering på problemet. Alkohol er fortsatt det viktigste rusmiddel i forhold til trafikksikkerheten. Samtidig har undersøkelser vist en relativt høy forekomst av andre rusmidler hos bilførere drept $\mathrm{i}$ eneulykker i Norge (21,5\%) (7), samt hos bilførere skadet i ulykker (24\%) (8), slik at fokusering på disse stoffene også er viktig for trafikksikkerheteten.

\section{REFERANSER}

1. Gjerde H, Mørland J. Repeat offences among drunken drivers. J Traffic Med 1990; 18 (4): 175-178.

2. Skurtveit S, Christophersen AS, Mørland J. Female drivers suspected for drunken or drugged driving. Forensic Sci Int 1995; 75: 139-148.

3. Skurtveit S, Christophersen AS, Mørland J. Kjøring under påvirkning av benzodiazepiner. Tidsskr Nor Lageforen 1995, 115 (2): 200-203.

4. Christophersen AS, Gjerde H, Bjørneboe A, Sakshaug J, Mørland J. Screening for drug use among Norwegian drivers suspected of driving under the influence of alcohol and drugs. Forensic Sci Int 1990; 45: 5-14.

5. Beylich KM, Christophersen AS, Skurtveit S, Bjørneboe A, Mørland J. En kartlegging av forekomsten av forskjellige rusmidler blant norske motorvognførere pågrepet av politiet med mistanke om påvirket kjøring. Norsk Epidemiologi 1996; 6 (1): 57-61.

6. Christophersen AS, Mørland J. Driving under the influence of drugs other than alcohol. Is Norway a special case? Proceeding of the 1994 joint TIAFT/SOFT international meeting. Spiehler V (Ed). Tampa, Florida, 1994, pp. 496-502.

7. Gjerde H, Beylich KM, Mørland J. Incidence of alkohol and drugs in fatally injured drivers in Norway. Accid Anal Prev 1993; 25: 479-483.

8. Christophersen AS, Beylich KM, Bjørneboe A, Fosser S, Glad A, Mørland J. Prevalence of alcohol and drugs in blood samples from Norwegian drivers involved in road traffic accidents. In: Proceedings of the 13th Int. Conf. on Alkohol, Drugs and Traffic Safety, Kloeden CN, MCLean AJ (Eds). Adelaide, 1995. ISBN 0908204-21-3, pp. 768-772. 